\title{
Contourite or turbidite?: magnetic fabric of fine-grained Quaternary sediments, Nova Scotia continental rise
}

\author{
A.N. Shor, D.V. Kent and R.D. Flood
}

\begin{abstract}
SUMMARY: Samples of three piston cores and one gravity core from the Nova Scotia continental rise (depths $4210-4925 \mathrm{~m}$ ) have been examined to differentiate parallel-to-slope and downslope depositional processes in Quaternary deposits from a region presently influenced by a strong contour current. Measurement of anisotropy of magnetic susceptibility of samples of a red-brown, silt-laminated lutite 'contourite' facies shows grain alignments which are consistent with both parallel-to-slope (contour current) flow and downslope (turbidity current) flow. We believe that these results provide support for the hypothesis that 'geologically significant' contour currents have influenced continental rise deposition during the Pleistocene. However, our observation that both alongslope and downslope alignments are present in lithologically similar units clearly demonstrates the need for studies on the relationship between lithofacies and process in this geological setting.
\end{abstract}

Contourites are sedimentary deposits in the deep ocean which are deposited by thermohalineinduced currents. The term 'contourite' was proposed by Hollister (1967) to describe a specific silt-laminated red-brown lutite facies observed in pre-Holocene samples from the continental rise off eastern North America. Subsequent investigations in regions of measured or inferred abyssal current flow have expanded the term to include a wide variety of sedimentary deposits ranging in texture from clay to sand-size, and with various structures and sorting characteristics (see Stow \& Lovell 1979, for a review). Recent investigations of the facies first described as 'contourites' by Hollister (1967) have questioned the role of contour currents in formation of the silt laminae and reinterpreted these deposits as fine-grained turbidites (Stow 1979; Stow \& Bowen 1980). The purpose of our present study is to identify sedimentary sequences which have been deposited beneath abyssal thermohaline flow so as to provide a baseline for subsequent descriptions of sedimentologic characteristics of the contourite facies.

Few students of sedimentation processes on the eastern Canadian margin would doubt that both turbidity currents and contour-following thermohaline bottom currents have been active agents of transport and deposition at various times in the past. Recent studies by HEBBLE (High Energy Benthic Boundary Layer Experiment) investigators demonstrate the presence of 'geologically significant' modern contour-following flow over the lower continental rise off Nova Scotia (Richardson et al. 1981). However, a fundamental question remains as to which process dominated on the continental rise during Pleisto- cene low stands of sea-level when sediment influx rates were substantially higher than today (Stanley et al. 1972), and when different abyssal circulation patterns may have prevailed in the Atlantic.

The method we use for identification of current-deposited sediments is the anisotropy of magnetic susceptibility (AMS), which is a measure of the preferential alignment or fabric of non-equidimensional silt- to sand-sized magnetic grains within a clay sediment matrix. The theoretical and experimental basis for using AMS as a determinant of flow during deposition of sediments is summarized by Hamilton \& Rees (1970). The technique has been applied to abyssal marine sediments to confirm the sedimentologic prediction of turbidity current deposition in La Jolla Submarine Canyon (Rees et al. 1968), to define regional patterns of current flow (Ellwood 1980; Auffret et al. 1981; Bulfinch et al. 1982; Rees et al. 1982), and to indicate changes in current strength with time through restricted abyssal passages (Ellwood \& Ledbetter 1979; Ledbetter \& Ellwood 1980). These latter studies, however, have relied mainly on the magnitude of anisotropy rather than its direction. Ellwood \& Ledbetter (1979) report ambiguous results in alignment directions from Vema Channel.

We report here on our initial results from examination of AMS parameters in three piston cores and one gravity core from the Nova Scotia continental rise (water depths 4210-4925 m). Piston core samples are mainly from pre-Holocene deposits, and include both silt-laminated and visually structureless clays. Gravity core samples include both Holocene calcareous muds and pre-Holocene (Wisconsin?) gravel-rich clays. 
Additional samples from a transect of piston cores from 4045 to $5025 \mathrm{~m}$ across the rise and from a set of box cores from 4800 to $5050 \mathrm{~m}$ are presently being examined.

\section{Regional setting}

Bathymetric studies (using surface-ship echosounding) and side-scan sonar studies (using the SIO/MPL Deep Tow instrument; Spiess \& Mudie 1970) show the presence of several lower rise channels and numerous shallow distributary channels or channel segments between $62^{\circ}$ and $63^{\circ} \mathrm{W}$ (Figs $1 \& 2$ ). Overall relief on the lower rise is extremely subdued, with regional gradients typically between 1:200 and 1:400. Channels rarely exceed $50 \mathrm{~m}$ in depth and have low, gently sloping walls (slopes typically $<1$ ). Where we have bottom photographs a dominantly clay interface with contour-parallel bottom currentgenerated bedforms was observed even in channel thalwegs.

The sediment cores come from relatively wellknown positions with respect to the local topography. The gravity core was located within one of the shallow distributary channels in the Deep Tow survey area (Fig. 2). The three piston cores were obtained from outside the Deep Tow survey area (Fig. 1). Although they are not precisely located relative to channel features, the shipboard $3.5 \mathrm{kHz}$ records near the piston core sites do not show channel relief, and acoustic penetration is substantially greater than within the surveyed region to the west. Graded beds and thick sand layers are rare to absent in piston cores $\mathrm{RC} 22-02$, 14 and 15 . These three cores were selected for study in part because they apparently do not represent channelized flow deposits.

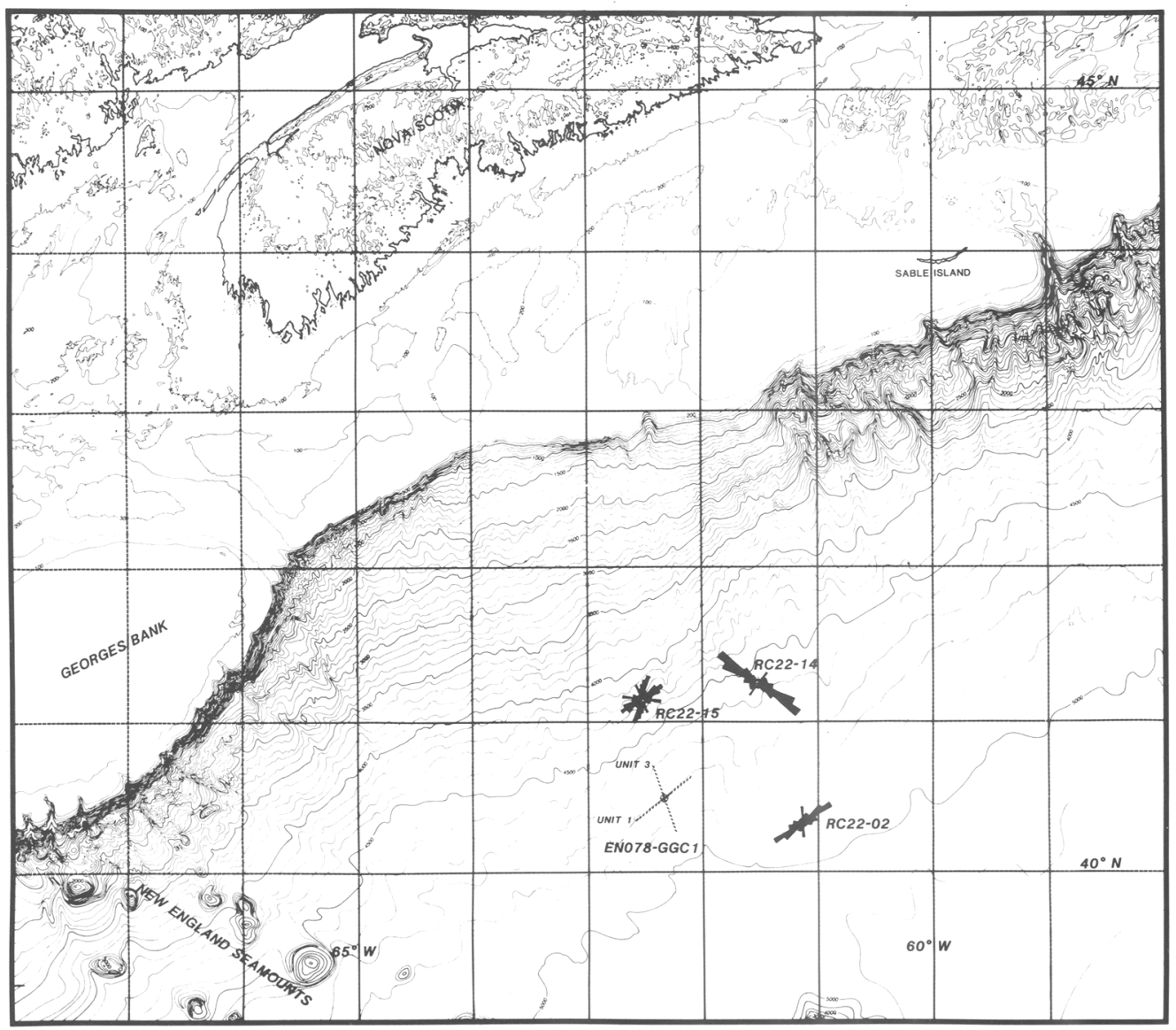

FIG. 1. Bathymetry of the Novia Scotia continental margin $(\mathrm{m})$. Rose diagrams at piston core sites summarize AMS alignment $\left(k_{\max }\right)$ in 10 intervals. Directions illustrated for gravity core EN-078-GGC 1 are mean values for three Holocene (Unit 1) and six pre-Holocene (Unit 3) samples. 


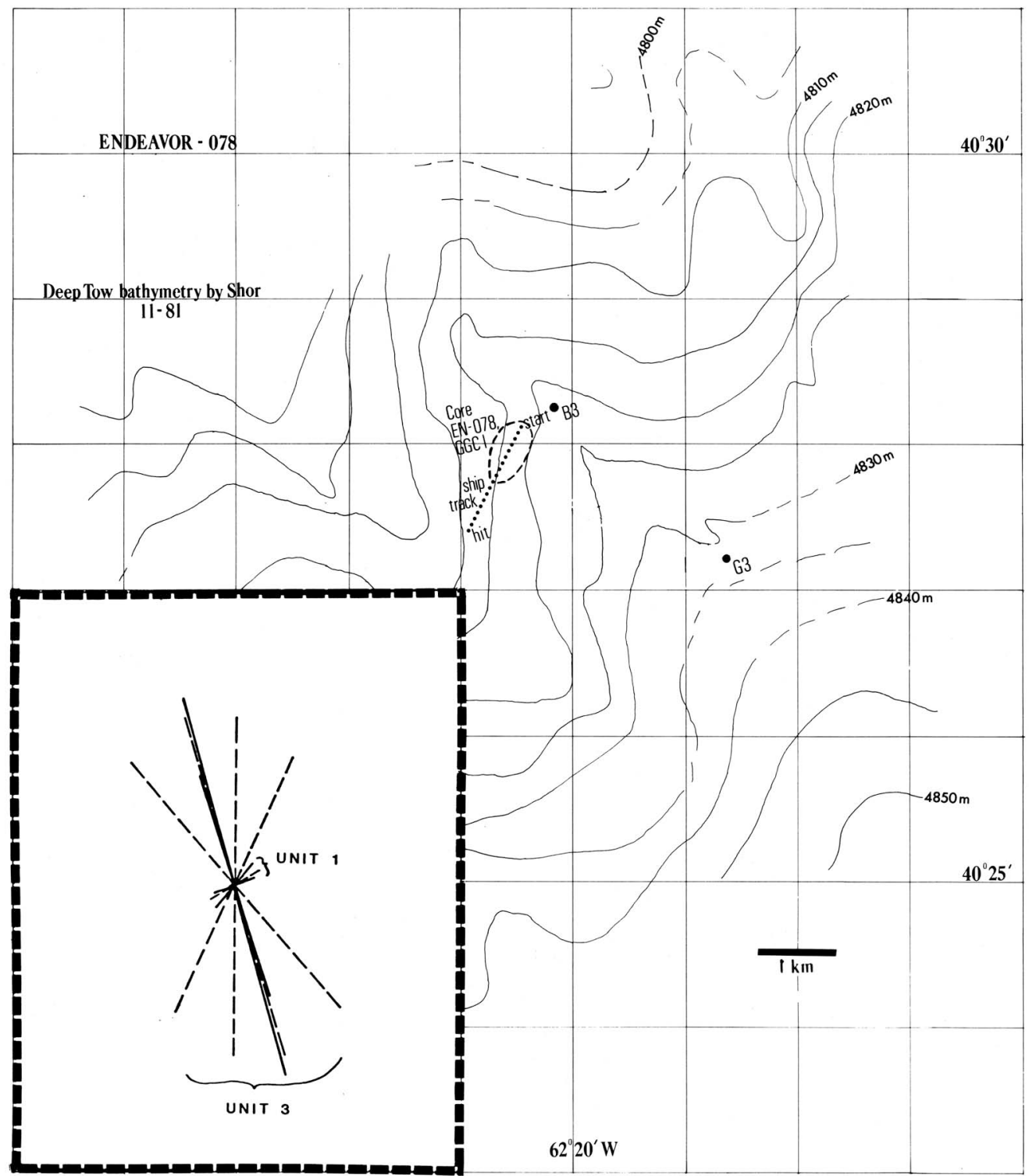

FIG. 2. Bathymetry near the site of the gravity core, illustrating distributary channel morphology. Contours from SIO/MPL Deep Tow survey. Ship was navigated relative to bottom transponders. Drift during coring is indicated as dotted tract. AMS alignments for the gravity core $\left(k_{\max }\right)$ as in Fig. 1.

\section{Holocene sediments}

Holocene sediments were recovered in a series of four box cores in the vicinity of the Deep Tow surveys on the lower rise (depths 4843-5048 m) collected on Knorr cruise 83. These cores contain lithologies ranging from fine-grained muds to contorted silts. The description of these sediments is briefly summarized here to demonstrate the complexity of depositional sequences and processes during the Holocene. The topmost surface layer in all box cores is a pale brown, faintly laminated slick clay from 2 to $10 \mathrm{~cm}$ thick, generally devoid of sand or silt, but with stringers of foraminiferal sand. This uppermost unit appears to be the one which is moulded into longitudinal bedforms by abyssal current flow (Tucholke 1982). 
In two cores deeper than $5035 \mathrm{~m}$ it is underlain by a very stiff layer composed predominantly of silt-sized mineral grains, variable in thickness $(5-15 \mathrm{~cm}$ thick) and strongly laminated with steeply dipping or strongly contorted beds. In the deepest core the lower contact is angular and irregular, and it contains clasts of the underlying clay. This unit is interpreted as a recent debrisflow, probably of limited extent, which may be related to the 1929 Grand Banks earthquake.

The principal Holocene sediment underlies these units and is a moderate yellowish-brown, foraminifera-rich, extensively bioturbated clay. Few primary sedimentary structures are preserved, although some horizontal banding is present. The unit ranges from 15 to more than 30 $\mathrm{cm}$ thick, and contains Holocene foraminifera ( $G$. menardii is present). It is the uppermost unit recovered in the gravity core and piston core 15 (piston cores 14 and 02 recovered no Holocene sediment).

A pale brown clay with faint horizontal lamination, similar in general texture and appearance to surficial sediments, underlies the calcareous clay, and grades downward into a complex group of mud, silt, and fine sand layers from 5 to $10 \mathrm{~cm}$ thick which range in colour from pale brown to dark yellow-brown. This coarse unit is laminated and cross-bedded, with cross-beds highlighted by pale brown clay. Foraminifera recovered from the sand layers are Holocene, indicating deposition within the last $\sim 11000 \mathrm{yr}$. This unit appears to be the 'spillover sand' reported by Stanley et al. (1972), and it was recovered in the gravity core.

\section{Channel deposits (core EN-078-GGC 1)}

A single large-diameter gravity core was recovered from the vicinity of $40^{\circ} 28^{\prime} \mathrm{N}, 62^{\circ} 21^{\prime} \mathrm{W}$ (depth $4830 \mathrm{~m}$ ) during Endeavor cruise EN-078 (Fig. 2). This gravity core is about $20 \mathrm{~km}$ from the nearest box core discussed above. The ship position was determined relative to the Deep Tow survey through ranging on two longlife transponders remaining at the site, so that the core location is known relative to bathymetry defined by Deep Tow, except for problems introduced by drift during coring. The core lies near the base of the western edge of a $15 \mathrm{~m}$ deep, $1 \mathrm{~km}$ wide distributary channel.

Three lithologies are recognized in the $83 \mathrm{~cm}$ long gravity core. The uppermost $17 \mathrm{~cm}$ is an olive-grey to yellowish-brown foraminiferal clay, of which the $\sim 20 \%$ coarse fraction consists principally of foraminiferal fragments and terrigenous sand. Whole foraminifera are present, but not common. Globorotalia menardii are present in this unit, indicating a Holocene Age $(<11000$ yr). Neither biologic nor physical sedimentary structures are obvious visually or in the X-radiograph, although a grossly parallel-laminated fabric is indicated.

Unit 2, from 17 to $22 \mathrm{~cm}$, is a graded sand unit principally composed of quartz and feldspar with ancillary rock fragments and terrigenous mineral grains, foraminifera and minor authigenic grains. At least two cross-bedded units are present in the upper $2 \mathrm{~cm}$ of the unit. Structures cannot be defined in the basal section due to partial collapse (a result of freezing during transport from the ship to the laboratory in mid-January, and subsequent thawing in a horizontal position). The sand is very poorly consolidated, and cross-bedding structures show no evidence of biogenic disruption. G. menardii are present in this unit, indicating a Holocene age; Uvigerina spp. suggest a source on the continental slope $(<2500 \mathrm{~m})$. We interpret this layer as a Holocene turbidite.

Unit 3 , from $22 \mathrm{~cm}$ to the base of the core, is an olive-grey gravel-rich clay. Carbonate content is very low. No foraminifera are observed in coarsefraction separates. Angular clasts up to $4 \mathrm{~cm}$ in diameter are very common, and include basalt and one mollusc fragment. This gravel-rich layer is quite different from glacial-aged sediments recovered in piston cores from elsewhere on this rise, and was not recovered in the box cores.

\section{Pre-Holocene sediments (piston cores)}

Over much of the Nova Scotia rise the pre-Holocene sediments consist of brown to reddishbrown slightly calcareous clays intercalated with discrete silt or sand layers. Although thick, coarse sand units are observed (and in some cases visibly graded (Hollister 1967; Horn et al. 1971; Hollister \& Heezen 1972), the prevalent facies consists of thin, parallel, silt laminae (generally $<1 \mathrm{~cm}$ thick), commonly in clusters, interbedded with a slightly calcareous silty clay. Silt layer frequency is highly variable, and in some instances may correlate from core to core (compare, for example, silt layer frequency in cores 14 and 15; Figs 4 \& 6).

Neither the age nor the origin of these deposits is well established, nor is it certain that the clay units and interbedded silt laminae are in fact derived from the same process. Both frequency of silt beds and individual bed thickness vary considerably. Average silt layer thicknesses appear to relate to proximity to major submarine channels (thicker beds near channels) based on examination of sand and silt layer frequency in the upper $5 \mathrm{~m}$ of 12 piston cores obtained during cruise RC22-09. In contrast, the frequency of occur- 
rence of coarse layers shows a pattern related to depth of water rather than proximity to source. Caution must be exercised in interpreting this type of data, however, because neither stratigraphic continuity nor accumulation rates are established for these deposits, and individual cores show pronounced variations downcore in both coarse layer frequency and thickness.

Previous interpretations of the silt-laminated pre-Holocene clays of the Nova Scotia rise have differed. Hollister (1967) suggests that they are most likely formed by bottom flows reworking the sediments, whereas Stow (1979) argues that they were deposited by turbidity currents. Therefore, we feel that it is important to determine whether the sediments retain a grain alignment. which might be preserved as an anisotropy in the magnetic susceptibility of the sediments, and which could then be used to define the direction of flow.

\section{Methods}

Anisotropy of magnetic susceptibility (AMS) measurements can be used to estimate the statistical grain orientiation of clastic sediments and therefore to allow inference about palaeocurrents and sedimentation conditions (Hamilton \& Rees 1970). For an assemblage of highly magnetic silt-sized or coarser grains, such as magnetite (which is commonly present in deep-sea sediments), the direction of the maximum susceptibility axis in a sample will correspond to the direction of preferred orientation of the longest axis of the magnetic grains. This direction is hypothesized to correspond to the orientation of the non-magnetic grain fraction as well. The magnetic method of sediment fabric determination is thus indirect, but it provides a quantitative description of grain alignment in three dimensions more rapidly than other direct grain orientation measurements. We describe the measuring techniques and basis for sample rejection in detail here since understanding the magnetic technique and its limitation is essential to interpreting the AMS results.

The susceptibility is estimated in the form of a second-rank symmetric tensor $k$ which relates the magnetization $\mathrm{J}_{\mathrm{i}}$ induced in a sample by a field $H_{\mathrm{j}}$ :

$$
J_{\mathrm{i}}=k_{\mathrm{ij}} H_{\mathrm{j}}
$$

The susceptibility may be specified completely by six quantities, three relating to the magnitude of the principal axes $\left(k_{\max } k_{\text {int }}\right.$, and $\left.k_{\min }\right)$ and three relating to their directions, which are orthogonal. We use a low-field torsion magnetometer (as described by King \& Rees 1962) employing an alternating field of up to $5172 \mathrm{~A} / \mathrm{m}(65 \mathrm{Oe})(\mathrm{rms})$ magnitude. Susceptibility differences are measured with this technique and a separate measurement of bulk susceptibility is made on an $\mathrm{AC}$ bridge to determine the magnitude of the principal susceptibility axes.

A check on the reliability of the measured data is obtained by a redundant measurement scheme. The best data values are found by a least square fit, and the differences between these optimized values for the susceptibility tensor and the original readings are calculated. An estimate of data reliability is obtained by comparing the root mean square value of these residuals to that of the optimized values. This measure of data reliability rarely exceeds $10 \%$ in the specimens measured here, indicating that specimen susceptibilities are in general adequately represented by a second order symmetric tensor. The few specimens with a data reliability measure exceeding $15 \%$ may have more complex susceptibilities, and are rejected from further analysis (Tables 1-4).

The results of the reliable AMS measurements are described in terms of the magnetic foliation plane, which is normal to the axis of minimum susceptibility, and the magnetic lineation within the foliation plane, which lies along the direction of the axis of maximum anisotropy. An indication of the degree of alignment is obtained from the parameter $h$, defined for this study as:

$$
h=\frac{k_{\text {max }}-k_{\text {min }}}{\left(k_{\text {max }}+k_{\text {min }}+k_{\text {int }}\right) / 3} \times 100
$$

and the parameter $q$ (Hamilton \& Rees 1970):

$$
q=\frac{k_{\max }-k_{\text {int }}}{\left(k_{\max }+k_{\text {int }}\right) / 2-k_{\min }}
$$

The parameter $h$ provides an estimate of the total anisotropy, the sum of both lineation and foliation. The parameter $q$ is a measure of the relative importance of the two fabric elements: foliation produced by gravitational settling of grains on a flat surface, and lineation resulting from aligning forces tangential to the bed. Values of $q$ vary from 0 (pure foliation) to 2 (pure lineation) with the change from dominantly foliar to dominantly linear fabric at a value of 0.67 .

Both the orientations of the principal susceptibility axes and the parameter $q$ can be calculated from susceptibility differences alone measured on the torsion magnetometer, whereas the parameter $h$ is also dependent on the bulk susceptibility. Measurement of bulk susceptibility is made on the less sensitive instrument and includes contributions from paramagnetic and diagenetic sediment components in addition to the ferromagnetic fraction that is thought to be primarily 
responsible for the observed susceptibility differences. Consequently, the magnitude of anisotropy (e.g. $h$ ) is much less precisely determined, and useful in a more qualitative sense than the orientation and shape of the susceptibility ellipsoid.

The results of measurement on laboratorydeposited and natural sediments have established the characteristics of a primary magnetic fabric induced by flowing water (Granar 1958; Rees 1965; Hamilton \& Rees 1970). The principal feature is a well-defined magnetic foliation in or near the bedding plane. The parameter $f$ (Crimes $\&$ Oldershaw 1967) gives the angular deviation of the $k_{\min }$ axis from the pole to bedding; in undisturbed sediments values of $f$ are usually less than $15^{\circ}$ (Hamilton \& Rees 1970; Rees \& Frederick 1974). Lineation is usually subordinate to foliation, and values of $q$ typically range from 0.06 to 0.67 . These characteristics reflect the expected dominant role of gravitation acting on grains during sedimentation.

Several types of secondary fabrics have been recognized and often result from postdepositional alteration of a primary fabric. Prevalent in deep-sea sediments are deformed fabrics, either resulting from the activity of burrowing organisms in the sediment (Rees et al. 1968) or due to coring disturbance (Rees \& Frederick 1974; Kent \& Lowrie 1975). In order to discriminate and reject specimens which have suffered modification of primary fabric, we applied a strict rejection criterion based on the value of parameter $f$. If $f$ exceeds $15^{\circ}$ (i.e. if foliation dips more than $15^{\circ}$ ), the measured specimen fabric is considered anomalous and rejected from consideration as an indicator of current flow direction. We feel that the data reliability parameter and $f$ constitute minimum criteria to reject samples for which fabrics are poorly-defined and have dominantly secondary (post-depositional) characteristics. For perspective, we note that Rees \& Frederick (1974) found in a study of DSDP cores that only 15 of 90 specimens with measurable anisotropy exhibited primary style fabrics.

Cores in the present study are assumed to have been taken vertically. The cores can be oriented in the horizontal plane by reference to magnetic remanent declinations measured on the samples for which anisotropy is determined. The remanent magnetization of each sample was determined after partial alternating field demagnetization to $23874 \mathrm{~A} / \mathrm{m}$ (to remove unstable or spurious components). Except for core intervals which show a pronounced trend (the top $3 \mathrm{~m}$ of core RC 22-14 and over the entire length of core RC 22-02), we believe that the mean declination provides an estimate of geographic north in these normal polarity, late Pleistocene sediments. The rotation in the two cores is attributed to twist during either coring or extrusion (probably the latter, as values in core RC 22-14 change in a core-coupling break). Mean declinations were therefore calculated either as linear regressions on depth (for twisted sections) or as simple means (for sections exhibiting no twist). Azimuths of the $k_{\max }$ axes for each core were oriented relative to mean declinations to place the magnetic fabric results in geographic coordinates.

Although an orienting technique using magnetic remanence of the sediment is the only one available for these cores, it presents a rather subtle problem that is difficult to resolve. It has been shown in laboratory redeposition experiments that certain processes of deposition can in some instances result in deflection of the remanence directions away from the geomagnetic field; alternatively, the geomagnetic field can exert an influence on anisotropy directions, especially in fine-grained sediment (Rees 1961; Rees \& Woodall 1975). It is therefore possible that the horizontal component of remanence (declination), which we use to orient the cores, and the direction of maximum anisotropy, which we assume is related to the axis of current flow, may not be completely independent of each other. Lack of independence tends to bring the $k_{\max }$ and remanence directions into coincidence and to obscure any relationship of $k_{\max }$ axes with current flow in geographic coordinates.

Figure 3 shows plots of the principal susceptibility directions $\left(k_{\max }\right.$ and $\left.k_{\min }\right)$ from cores $\mathrm{RC} 22-14$ and $\mathrm{RC} 22-02$. The reference azimith $(\mathrm{N})$ in each plot is the mean remanent declination calculated for each sample level as outlined above. Also shown is the measured mean remanent inclination for each core and the inclination expected for a geocentric axial dipole field at the core latitude.

The remanent inclination is on average shallower than the expected value in each core. The discrepancy can be interpreted as an inclination error', due to the influence of hydrodynamic and gravitational torques on the magnetic particles during acquisition of a detrital or depositional remanent magnetization. Although a bias of remanent inclinations into the magnetic foliation plane thus appears to exist, the extent of a corresponding bias of remanent declinations toward the magnetic lineations ( $k_{\max }$ axes) is difficult to assess due to the absence of a suitable, independent frame of reference. However, considering the subordinate role of lineation compared to foliation in the magnetic fabric of these sediments, the remanent declinations would not be expected to be greatly deflected toward the 

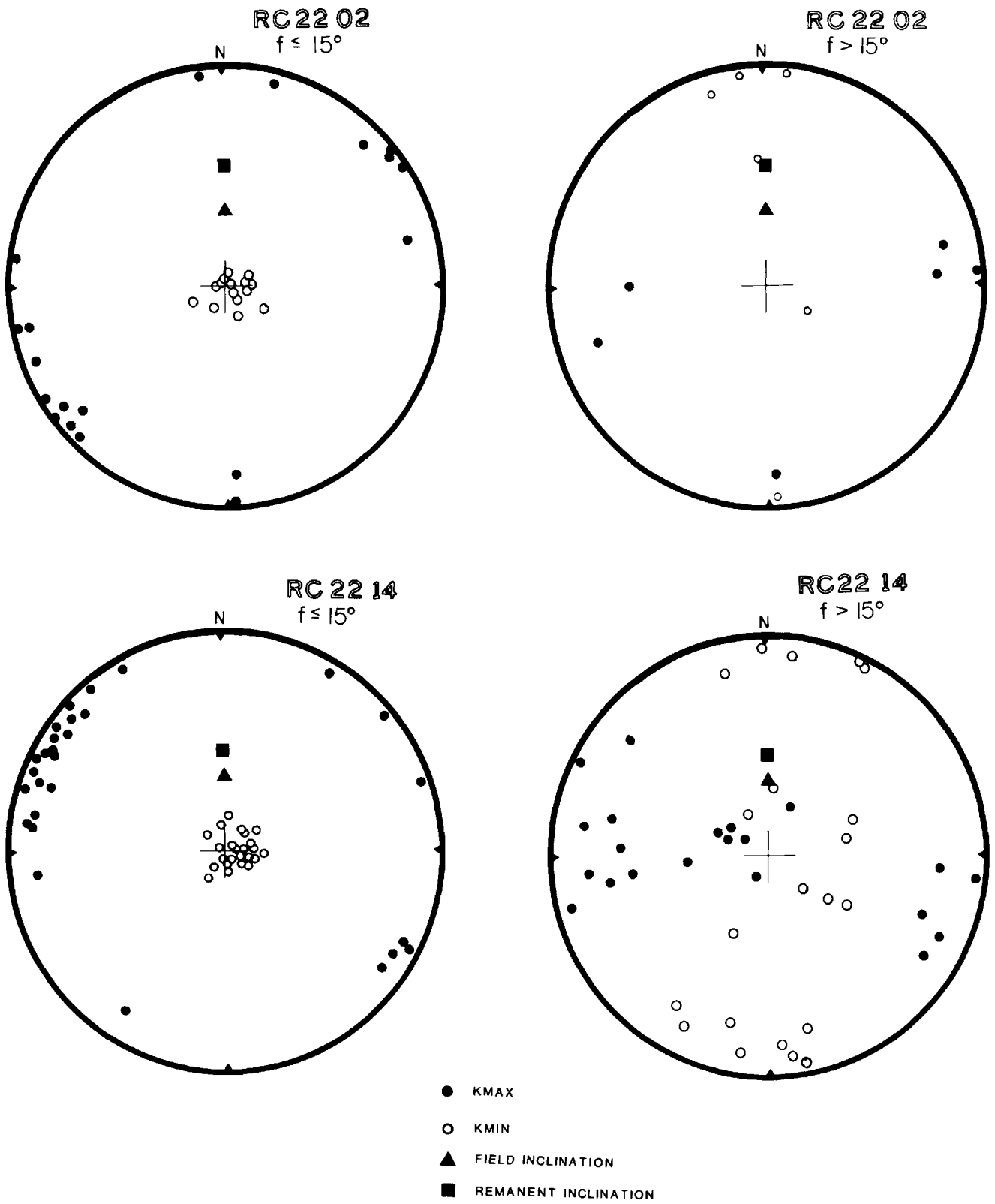

FIG. 3. Stereographic plots of magnetic remanence and susceptibility anisotropy directions in piston cores RC22-02 (top) and RC22-14 (bottom). Panels on left show anisotropy data consistent with a primary fabric $\left(f \leqslant 15^{\circ}\right)$; panels on right are anisotropy data rejected for paleocurrent analysis in each case due to high values of $f\left(>15^{\circ}\right.$ ). The reference azimuth $(\mathrm{N})$ is the mean remanent declination calculated for each sample level as discussed in text. Mean remanent inclinations (42.5 for RC22-02 and 49.8 for RC22-14) are compared to axial dipole values at core sites.

lineation directions. Of more concern is the possibility of a systematic convergence of $k_{\max }$ and remanent declination directions due to field control on anistropy in such fine-grained sediments. However, the combination of steep field inclination (about 60 ) and selection of magnetic fabrics with near horizontal foliation planes ( $f$ less than 15 ) should help to minimize the effect of the geomagnetic field on the anisotropy data set used for palaeocurrent analysis in these cores (e.g. 
Rees 1961). Detailed analyses of magnetic grain compositions and sizes are needed to further constrain the origin and significance of the magnetic susceptibility anisotropy in these sediments. With presently available information, we already see no obvious variation of down-core declination directions related to gross sediment lithology.

Finally, we point out that alignment azimuths $\left(k_{\max }\right)$ are not simple vector quantities, but rather are bi-directional; alignment directions are standardized here to refer to the downward dip of the $k_{\max }$ axis. However, the reader should be aware that all reported $k_{\max }$ directions have conjugate values, $180^{\circ}$ different, and that the method described herein provides only an alignment and not an actual flow direction.

\section{Results}

\section{Piston core RC22-14 (4559 m)}

The magnetic fabric and remanence of 54 samples were measured from core RC22-14 between 14 $\mathrm{cm}$ and $965 \mathrm{~cm}$ (Table $1 \&$ Fig. 4). Twenty-three samples were rejected for palaeocurrent analysis based on values of $f$ exceeding 15 (foliation deviating from horizontal); two of these same samples also displayed a high rms error.

Apparent declinations (corer frame of reference) show severe core twist over the upper $3 \mathrm{~m}$ (greater than $180^{\circ}$ twist between $80 \mathrm{~cm}$ and 295 $\mathrm{cm})$. North directions at each sample level were calculated from a linear regression of declination on depth, and azimuths of magnetic anisotropy $\left(k_{\max }\right)$ were oriented to geographic coordinates using the regression line estimates of true north. The measured sample declination was used to orient the sample at $45 \mathrm{~cm}$. Declinations from 300 $\mathrm{cm}$ to the bottom of the core showed no evidence of core twist, and the mean declination value of $65^{\circ}$ was used to orient these samples to geographic north.

Magnetic results show three discrete units in the core, each corresponding with a lithologic unit. The uppermost $225 \mathrm{~cm}$ (Unit I) shows a bimodal set of primary fabric $k_{\max }$ orientations, with four samples aligned along a trend of $115-145^{\circ}$ and five samples along the nominally orthogonal trend of $210-245$. Two samples in this unit were rejected. Unit II $(225-475 \mathrm{~cm})$, in which 11 samples were measured, contains no sample in which a primary fabric alignment determination is possible. Values of $f$ exceed 30 " for all samples, and exceed $70^{\circ}$ in nine samples. The deepest unit (Unit III; 475-970 cm), displays a predominant alignment along $110^{\circ}$, with all but one of 22 samples between 90 and 130 . Ten additional samples were rejected from this unit. The dominant fabric orientation is near to the downslope direction at this site suggesting that these sediments may have been deposited by turbidity flows.

The apparent disruption of primary magnetic fabric in Unit II is of some interest, since remanence of this unit shows normal results (positive, steep inclinations, with declinations consistent internally and with the unit below). The most reasonable processes for disturbing fabric but not NRM are bioturbation or possibly debris-flow emplacement involving severe liquifaction. Bioturbation might reasonably be expected to disrupt the original magnetic fabric while remanence is not locked in until sediments are buried below the burrowing zone (Kent 1973). If debris-flow transport is responsible, then it is necessary to infer that the entire deposited layer is remagnetized into the field at the time of deposition. Although there is a clear difference in carbonate content of Unit II relative to the remainder of the core, this unit is not necessarily allochthonous based on this criterion alone. At present we prefer the interpretation that bioturbation has altered the sediment fabric and possibly destroyed any laminations in this interval.

\section{Piston core RC22-02 (4925 m)}

Twenty-six samples were examined between 9 and $564 \mathrm{~cm}$ (Table $2 \&$ Fig. 5). Six samples were rejected based on excessively large values of $f$. Declinations showed no evidence of core twist, and the core mean of 100 was subtracted from all AMS azimuths to align samples in geographic coordinates. Sixteen of the 20 acceptable samples show $k_{\max }$ azimuths within $30^{\circ}$ of the regional contour trend of $235^{\circ}$. Unlike core RC 22-14, no correspondence was observed between interval $k_{\max }$ azimuth and lithology. Neither of two samples from the uppermost lithologic unit (Unit I; $0-22 \mathrm{~cm}$ ) provided acceptable primary magnetic fabric, most likely because of disturbance during coring and subsequent handling (Kent \& Lowrie 1975). This carbonate-enriched zone, which is commonly missed in the piston cores from the region, is inferred to be Holocene. A similar lithologic unit is discussed in the results for the gravity core.

Lithologic Unit II $(22-231 \mathrm{~cm})$ is similar in most respects to Unit I of core RC22 14. Three of eight samples were rejected. Of the remaining samples, four were aligned within $30^{\circ}$ of the contour trend. The lowermost sample in this unit shows alignment more closely approximating the downslope trend. There are two $2 \mathrm{~cm}$ sand layers in the $11 \mathrm{~cm}$ which are below this sample 
TABLE 1. Piston core RC22-14 41 $14.8^{\prime} \mathrm{N} ; 61^{\circ} 31.8^{\prime} \mathrm{W} ; 4559 \mathrm{~m}$

\begin{tabular}{|c|c|c|c|c|c|c|c|c|}
\hline $\begin{array}{c}\text { Sample } \\
\text { depth }(\mathrm{cm})\end{array}$ & Inclination & Declination & $\begin{array}{c}\text { Mean } \\
\text { declinationt }\end{array}$ & $\begin{array}{c}A=i m u t h \\
\left(k_{\text {max }}\right)\end{array}$ & $\begin{array}{c}\text { Geographic } \\
\text { alignment }\end{array}$ & $f$ & $q$ & $h$ \\
\hline \multicolumn{9}{|l|}{ Unit I } \\
\hline 14 & 37.5 & 063.4 & & $325.1 *$ & & 20.0 & .91 & $7.7 \%$ \\
\hline 45 & 70.9 & 186.4 & $(186.4)$ & 305.9 & 119.5 & 9.6 & 1.01 & 23.1 \\
\hline 80 & 59.8 & 261.7 & 265.8 & 337.9 & 072.1 & 1.6 & .54 & 25.0 \\
\hline 91 & 62.0 & 292.7 & 275.7 & 164.0 & 248.3 & 5.8 & .56 & 18.1 \\
\hline 110 & 63.9 & 301.2 & 292.6 & 343.7 & 051.1 & 1.1 & .27 & 22.6 \\
\hline 123 & 57.5 & 294.1 & 304.3 & 336.3 & 032.0 & 4.1 & .25 & 32.2 \\
\hline 164 & 40.0 & 334.5 & & $177.3^{*}$ & & 22.5 & .15 & 14.3 \\
\hline 176 & 52.6 & 345.9 & 351.6 & 204.2 & 212.6 & 14.0 & .21 & 18.9 \\
\hline 194 & 37.6 & 357.8 & 007.7 & 125.6 & 117.9 & 14.9 & .17 & 31.3 \\
\hline 201 & 55.4 & 009.9 & 014.0 & 324.9 & 310.9 & 8.1 & .20 & 19.3 \\
\hline 212 & 44.4 & 015.8 & 023.8 & 345.5 & 321.7 & 2.0 & .19 & 33.4 \\
\hline \multicolumn{9}{|l|}{ Unit II } \\
\hline 255 & 30.4 & 073.1 & & $186.6^{*}$ & & 16.1 & .37 & 8.3 \\
\hline 264 & 43.8 & 088.8 & & $095.0^{*}$ & & 71.0 & .30 & 7.4 \\
\hline 274 & 44.9 & 085.3 & & $279.3^{*}$ & & 81.9 & .84 & 5.3 \\
\hline $295_{t}^{+}$ & 51.0 & 085.2 & & $019.7^{*}$ & & 78.3 & .39 & 2.0 \\
\hline $323^{\circ}$ & 66.6 & 050.9 & & $335.0^{*}$ & & 71.5 & .31 & 6.4 \\
\hline 333 & 66.6 & 050.0 & & $334.4^{*}$ & & 87.1 & 1.05 & 6.9 \\
\hline 344 & 60.6 & 050.6 & & $166.1^{*}$ & & 82.3 & .45 & 6.0 \\
\hline $365_{+}^{+}$ & 56.7 & 067.0 & & $331.4^{*}$ & & 87.9 & .35 & 39.4 \\
\hline $372^{+}$ & 57.2 & 057.5 & & $330.1^{*}$ & & 36.0 & 1.85 & 9.1 \\
\hline 385 & 55.4 & 046.8 & & $325.3^{*}$ & & 77.0 & 1.24 & 4.6 \\
\hline 465 & 76.7 & 048.0 & & $014.3^{*}$ & & 82.7 & 1.46 & 8.4 \\
\hline \multicolumn{9}{|l|}{ Unit III } \\
\hline 486 & 66.3 & 047.6 & & $344.9^{*}$ & & 17.9 & .78 & $6.6 \%$ \\
\hline 500 & 66.8 & 053.4 & 64.9 & 342.1 & 277.2 & 10.1 & .18 & 11.6 \\
\hline 507 & 67.8 & 051.4 & 64.9 & 329.3 & 264.4 & 11.2 & .12 & 24.7 \\
\hline 524 & 71.0 & 068.3 & & $338.6^{*}$ & & 34.3 & 1.25 & 4.0 \\
\hline 561 & 59.5 & 090.5 & & $347.8^{*}$ & & 28.3 & .70 & 10.0 \\
\hline 574 & 57.4 & 078.4 & 64.9 & 344.8 & 279.9 & 6.0 & .70 & 9.3 \\
\hline 606 & 48.5 & 065.0 & 64.9 & 346.1 & 281.2 & 8.9 & .88 & 15.0 \\
\hline 622 & 45.8 & 063.9 & 64.9 & 353.6 & 288.7 & 3.3 & .32 & 18.8 \\
\hline 633 & 42.7 & 071.3 & 64.9 & 010.5 & 305.6 & 9.6 & .21 & 10.5 \\
\hline 642 & 47.1 & 064.0 & 64.9 & 009.1 & 304.2 & 8.2 & .15 & 15.6 \\
\hline 647 & 44.2 & 063.9 & 64.9 & 010.1 & 305.2 & 5.1 & .19 & 18.9 \\
\hline 670 & 35.1 & 063.7 & 64.9 & 020.4 & 315.5 & 7.4 & .06 & 19.9 \\
\hline 682 & 25.2 & 058.6 & 64.9 & 014.2 & 309.3 & 8.9 & .15 & 21.3 \\
\hline 686 & 50.6 & 070.0 & & $000.4^{*}$ & & 89.2 & .75 & 3.8 \\
\hline 695 & 46.9 & 075.0 & 64.9 & 011.7 & 306.8 & 13.8 & .49 & 8.6 \\
\hline 702 & 56.8 & 067.7 & & $160.2^{*}$ & & 69.3 & .33 & 4.2 \\
\hline 722 & 45.9 & 067.4 & 64.9 & 013.2 & 308.3 & 5.9 & .29 & 21.2 \\
\hline 747 & 62.1 & 074.4 & & $002.1^{*}$ & & 31.8 & 1.33 & 12.7 \\
\hline 765 & 53.2 & 072.7 & 64.9 & 358.7 & 293.8 & 6.7 & .36 & 14.4 \\
\hline 770 & 60.1 & 067.2 & & $359.5^{*}$ & & 89.4 & .51 & 3.5 \\
\hline 776 & 57.3 & 077.5 & 64.9 & 192.3 & 127.4 & 8.4 & .46 & 7.6 \\
\hline 783 & 51.0 & 090.1 & & $016.5^{*}$ & & 29.8 & 1.17 & 4.7 \\
\hline 793 & 43.4 & 093.1 & 64.9 & 355.9 & 291.0 & 13.5 & .26 & 2.3 \\
\hline 813 & 20.4 & 085.2 & 64.9 & 187.8 & 122.9 & 9.5 & .10 & 10.5 \\
\hline 829 & 35.9 & 070.2 & & $176.5^{*}$ & & 78.4 & .56 & 2.8 \\
\hline 855 & 36.7 & 046.8 & 64.9 & 004.9 & 300.0 & 7.5 & .15 & 14.3 \\
\hline 863 & 32.5 & 042.5 & 64.9 & 006.4 & 301.5 & 6.6 & .04 & 10.7 \\
\hline 868 & 30.2 & 042.7 & 64.9 & 356.4 & 291.5 & 7.2 & .05 & 21.5 \\
\hline 875 & 32.1 & 045.1 & 64.9 & 004.5 & 299.6 & 4.2 & .18 & 23.6 \\
\hline 907 & 27.0 & 028.4 & 64.9 & 003.5 & 298.6 & 10.2 & .14 & 27.9 \\
\hline 927 & 28.8 & 036.1 & 64.9 & 019.2 & 314.3 & 10.0 & .05 & 49.6 \\
\hline 965 & 46.9 & 012.3 & & $193.7^{*}$ & & 24.8 & .14 & 9.2 \\
\hline
\end{tabular}

$* \mathrm{f}>15$

$\dagger \sigma=10.5$ for Unit I; $\sigma=16.5$ for Unit III

\pm rms error $>15^{\circ}$ \%

Inclination, declination following demagnetization to $23874 \mathrm{~A} / \mathrm{m}$. 


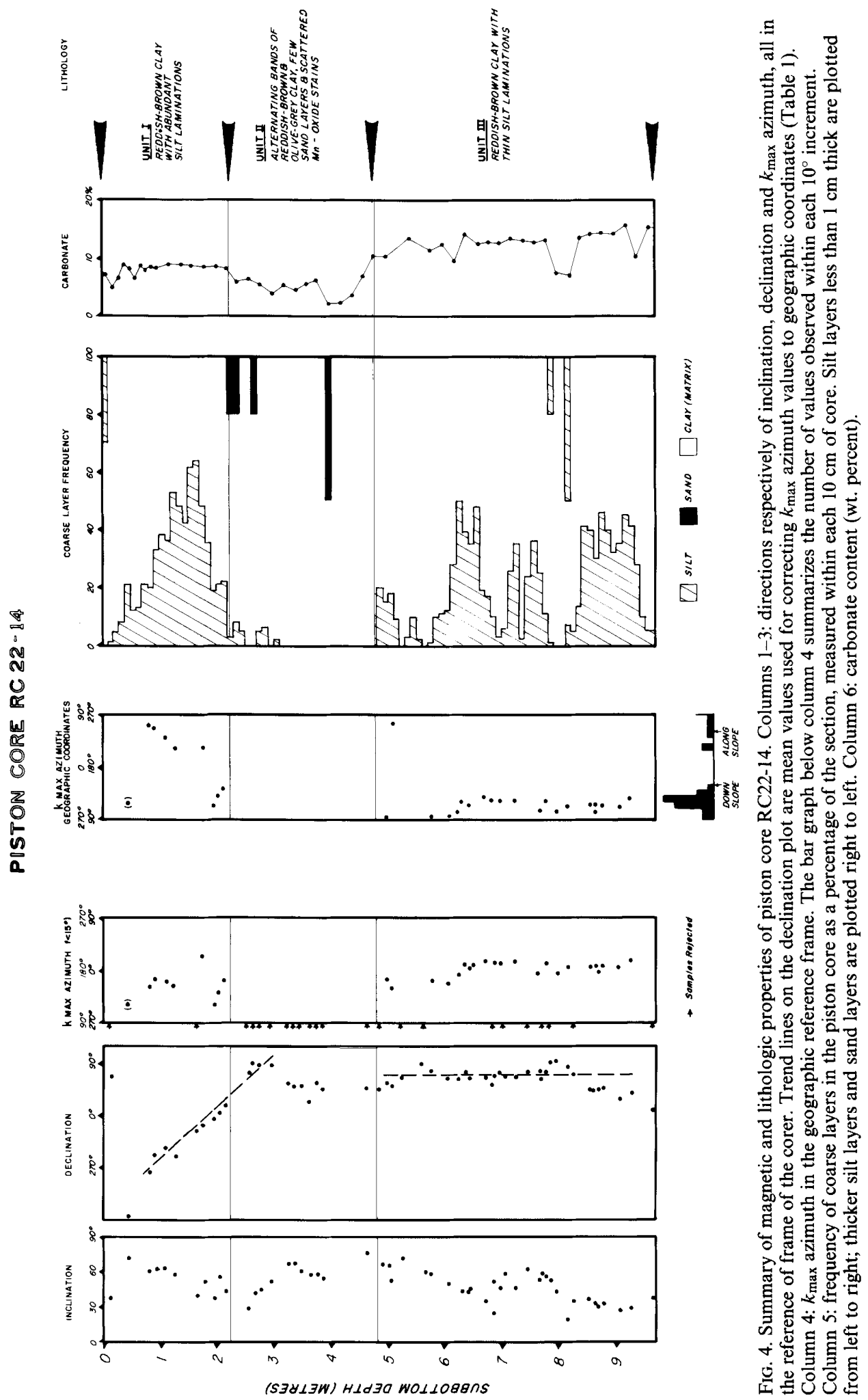


TABLE 2. Piston core $22-0240^{\circ} 19.7^{\prime} \mathrm{N} ; 61^{\circ} 06.1^{\prime} \mathrm{W} ; 4925 \mathrm{~m}$

\begin{tabular}{|c|c|c|c|c|c|c|c|c|}
\hline $\begin{array}{c}\text { Sample } \\
\text { depth }(\mathrm{cm})\end{array}$ & Inclination & Declination & $\begin{array}{c}\text { Mean } \\
\text { declination } \dagger\end{array}$ & $\begin{array}{c}\text { Azimuth } \\
\left(k_{\max }\right)\end{array}$ & $\begin{array}{c}\text { Geographic } \\
\text { alignment }\end{array}$ & $f$ & $q$ & $h$ \\
\hline \multicolumn{9}{|l|}{ Unit I } \\
\hline 9 & $49.5^{\circ}$ & $096.0^{\circ}$ & & $187.0^{*} *$ & & $89.8^{\circ}$ & .34 & $4.6 \%$ \\
\hline 18 & 37.2 & 118.7 & & $101.2^{*}$ & & 86.1 & .32 & 4.6 \\
\hline \multicolumn{9}{|l|}{ Unit II } \\
\hline 87 & 28.1 & 102.1 & $100.0^{\circ}+$ & 154.4 & $054.4^{\circ}$ & 10.2 & .85 & 2.4 \\
\hline 107 & 18.5 & 098.4 & 100.0 & 359.5 & 259.5 & 7.9 & .28 & 13.5 \\
\hline 132 & 30.8 & 076.5 & & $186.3^{*}$ & & 88.8 & .37 & 4.0 \\
\hline 145 & 33.5 & 072.4 & & $352.1^{*}$ & & 50.3 & 1.54 & 5.5 \\
\hline 173 & 42.4 & 051.2 & & $177.5^{*}$ & & 83.3 & .28 & 2.8 \\
\hline 190 & 52.1 & 098.3 & 100.0 & 153.4 & 053.4 & 13.1 & .53 & 12.9 \\
\hline 211 & 39.1 & 106.8 & 100.0 & 309.6 & 209.6 & 2.2 & .19 & 14.1 \\
\hline 220 & 47.8 & 123.2 & 100.0 & 094.7 & 355.3 & 10.0 & .33 & 3.6 \\
\hline \multicolumn{9}{|l|}{ Unit III } \\
\hline 263 & 47.7 & 108.4 & 100.0 & 324.7 & 224.7 & 7.1 & .33 & 7.6 \\
\hline 279 & 43.0 & 089.3 & 100.0 & 333.6 & 233.6 & 8.3 & .26 & 8.3 \\
\hline 282 & 39.0 & 087.9 & 100.0 & 327.8 & 227.8 & 4.9 & .32 & 10.6 \\
\hline 319 & 25.0 & 107.6 & 100.0 & 338.4 & 238.4 & 5.8 & .18 & 26.9 \\
\hline 324 & 23.1 & 106.1 & 100.0 & 329.3 & 229.3 & 13.2 & .39 & 5.5 \\
\hline 329 & 36.9 & 102.2 & & $000.7^{*}$ & & 16.8 & .33 & 11.1 \\
\hline 338 & 35.3 & 102.5 & 100.0 & 277.7 & 177.7 & 6.7 & .11 & 7.9 \\
\hline 352 & 56.0 & 103.0 & 100.0 & 114.9 & 014.9 & 2.4 & .22 & 7.7 \\
\hline 385 & 57.1 & 090.1 & 100.0 & 156.7 & 056.7 & 2.3 & .41 & 11.4 \\
\hline 402 & 53.6 & 091.0 & 100.0 & 000.7 & 260.7 & 1.3 & .21 & 11.0 \\
\hline \multicolumn{9}{|l|}{ Unit IV } \\
\hline 425 & 69.3 & 119.3 & 100.0 & 332.7 & 232.7 & 3.5 & .29 & 7.9 \\
\hline 444 & 56.3 & 101.9 & 100.0 & 346.7 & 246.7 & 7.3 & .18 & 20.5 \\
\hline 472 & 60.4 & 111.8 & 100.0 & 348.8 & 248.8 & 7.9 & .16 & 17.2 \\
\hline 504 & 32.8 & 123.3 & 100.0 & 177.5 & 077.5 & 13.6 & .06 & 24.8 \\
\hline 532 & 37.4 & 109.3 & 100.0 & 019.3 & 279.3 & 3.0 & .04 & 26.8 \\
\hline 565 & 53.7 & 102.7 & 100.0 & 144.7 & 044.7 & 7.1 & .25 & 15.0 \\
\hline
\end{tabular}

$* \mathrm{f}>15$

$+\sigma=16.0$

Inclination, declination following demagnetization to $23874 \mathrm{~A} / \mathrm{m}$.

suggesting that we may have sampled a portion of a fine-grained turbidite.

Unit III $(231-402 \mathrm{~cm})$ is visually similar to Unit II of RC22-14 with interbedded greyishbrown and reddish-brown clays. Silt laminations are more frequent in core $\mathrm{RC} 22-02$, however, and $\mathrm{Mn}$-oxide stains are not observed. Only one of 10 samples were rejected for anisotropy, and seven of the remaining samples were closely aligned with the regional contours. Only one sample shows a predominantly downslope alignment.

Unit IV $(402-587 \mathrm{~cm})$ is similar to Unit II above, with somewhat more abundant silt layering. All six measured values produced acceptable primary fabrics, and all lie closer to the contour trend than the downslope direction.

\section{Piston core RC22-15 (4210 m)}

Thirty samples were analysed between 3 and 476 cm (Table 3; Fig. 6). Five additional samples between 483 and $585 \mathrm{~cm}$ were also examined (the deepest is from flow-in at the bottom of the core). This latter group of samples is not discussed due to problems in interpretation of NRM below a tray break at $480 \mathrm{~cm}$. Of the 30 samples, only one is rejected based on the criterion of large dip in anisotropy $\left(f>15^{\circ}\right)$. One sample with $f=15^{\circ}$ is retained in the present discussion.

Lithologies in core RC $22-15$ are not readily comparable to those observed in cores RC 22-02 or RC 22-14. The core consists predominantly of pale brown clay, and contains abundant silt laminae above $230 \mathrm{~cm}$. Four units have been 


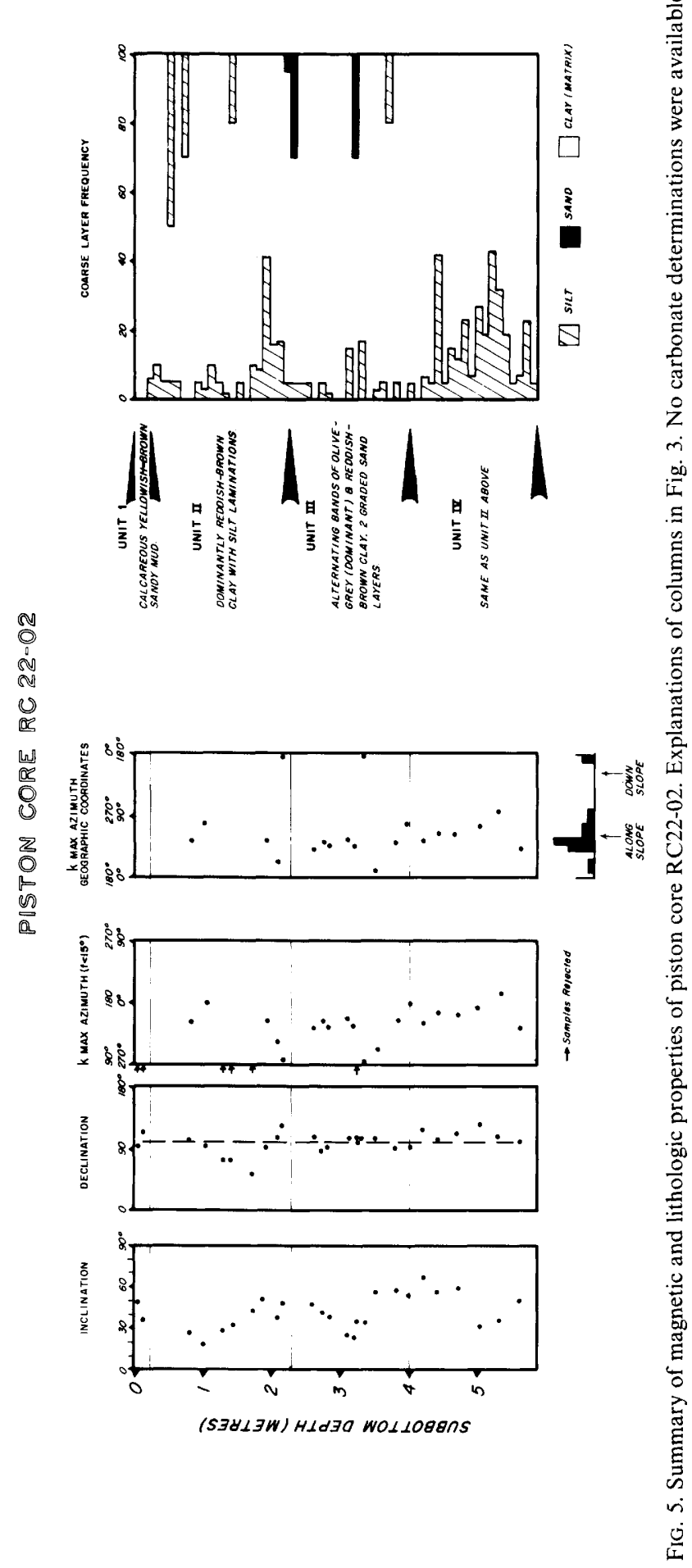


TABle 3. Piston core $22-1541^{\circ} 08.4^{\prime} \mathrm{N} ; 62^{\circ} 30.5^{\prime} \mathrm{W} ; 4210 \mathrm{~m}$

\begin{tabular}{|c|c|c|c|c|c|c|c|c|}
\hline $\begin{array}{c}\text { Sample } \\
\text { depth }(\mathrm{cm})\end{array}$ & Inclination & Declination & $\begin{array}{c}\text { Mean } \\
\text { declination } \dagger\end{array}$ & $\begin{array}{c}\text { Azimuth } \\
\left(k_{\max }\right)\end{array}$ & $\begin{array}{c}\text { Geographic } \\
\text { alignment }\end{array}$ & $f$ & $q$ & $h$ \\
\hline 3 & 25.6 & 129.8 & 105.5 & 166.5 & 061.0 & 7.2 & .17 & $51.9 \%$ \\
\hline 33 & 56.2 & 103.0 & 115.9 & 126.2 & 010.3 & 4.7 & .13 & 24.5 \\
\hline 44 & 49.8 & 132.8 & 119.7 & 354.7 & 235.0 & 3.7 & .48 & 6.2 \\
\hline 53 & 34.8 & 118.4 & 122.9 & 282.3 & 159.4 & 1.8 & .03 & 14.9 \\
\hline 74 & 30.6 & 118.6 & 130.1 & 359.0 & 228.9 & 0.9 & .05 & 24.7 \\
\hline 93 & 25.2 & 142.8 & 136.8 & 331.7 & 194.9 & 4.6 & .05 & 25.9 \\
\hline 106 & 30.2 & 159.6 & 141.3 & 184.1 & 042.8 & 4.3 & .14 & 24.7 \\
\hline 113 & 37.6 & 155.0 & 143.7 & 075.2 & 111.3 & 2.7 & .07 & 18.2 \\
\hline 116 & 34.2 & 155.3 & 144.7 & 064.0 & 279.3 & 7.9 & .07 & 21.3 \\
\hline 134 & 27.9 & 154.7 & 151.0 & 324.7 & 173.7 & 8.3 & .02 & 27.5 \\
\hline 147 & 40.2 & 148.4 & 155.5 & 351.4 & 195.9 & 4.5 & .13 & 26.1 \\
\hline 167 & 31.1 & 155.5 & 162.5 & 321.4 & 158.9 & 7.1 & .06 & 16.5 \\
\hline 193 & 38.3 & 164.7 & 171.5 & 145.5 & 334.0 & 9.8 & .04 & 30.6 \\
\hline 221 & 36.9 & 185.0 & 181.2 & 268.8 & 087.6 & 5.3 & .12 & 21.3 \\
\hline 234 & 40.8 & 193.2 & 185.8 & 046.5 & 220.7 & 15.0 & .07 & 16.6 \\
\hline 253 & 40.7 & 191.4 & 192.4 & 081.1 & 248.7 & 5.7 & .08 & 34.4 \\
\hline 284 & 48.7 & 201.0 & 203.1 & 082.5 & 239.4 & 3.1 & .13 & 19.7 \\
\hline 305 & 39.1 & 231.0 & 210.5 & 289.1 & 078.6 & 5.0 & .10 & 28.1 \\
\hline 345 & 47.4 & 219.2 & 224.4 & 278.9 & 054.5 & 6.7 & .09 & 10.0 \\
\hline 352 & 40.9 & 215.4 & 226.8 & 323.4 & 096.6 & 2.5 & .10 & 10.3 \\
\hline 375 & 38.0 & 222.6 & 234.8 & 295.7 & 060.9 & 3.0 & .10 & 10.0 \\
\hline 384 & 38.0 & 231.8 & 237.9 & 223.3 & 345.3 & 2.7 & .02 & 30.3 \\
\hline 393 & 40.6 & 211.3 & & $126.9^{*}$ & & 59.1 & .29 & 31.8 \\
\hline 404 & 63.2 & 259.9 & 244.9 & 241.5 & 356.6 & 12.7 & .26 & 11.8 \\
\hline 415 & 46.3 & 259.9 & 248.7 & 248.8 & 000.1 & 9.8 & .22 & 5.8 \\
\hline 437 & 42.8 & 270.1 & 256.3 & 263.3 & 007.0 & 1.0 & .51 & 12.5 \\
\hline 441 & 59.9 & 259.0 & 257.7 & 285.2 & 027.5 & 14.7 & 31 & 11.6 \\
\hline 446 & 60.9 & 250.9 & 259.5 & 353.0 & 093.5 & 5.1 & .15 & 20.9 \\
\hline 464 & 50.7 & 273.4 & 265.7 & 274.1 & 008.4 & 6.7 & .03 & 36.4 \\
\hline 476 & 53.0 & 261.1 & 269.9 & 284.5 & 014.6 & 2.9 & .04 & 24.2 \\
\hline
\end{tabular}

described as possible debris-flows, varying from 12 to $70 \mathrm{~cm}$ thick, based on their coarse texture, lack of parallel lamination, and the presence of larger clasts both of rock fragments and deformed soft sediments. These units, however, show normal NRM directions, consistent with those of bounding lithologic units.

Azimuths of $k_{\max }$ are more variable in this core than in either of the other two piston cores. No notable correspondence is observed between lithologic properties and magnetic properties. Even excluding the samples from units described as debris-flow, no clear pattern emerges in $k_{\max }$ direction, and the sample values instead show a broad distribution around the compass. However, the region between $280^{\circ}$ and $330^{\circ}$ (NW/SE) contains only a single sample. We are not certain if further sample analysis will improve the separation of azimuth groupings. The shallowest sample, from $3 \mathrm{~cm}$, comes from the calcareous unit commonly observed near the top of gravity cores and box cores from the region, and shows a grain alignment parallel to contours, similar to that observed in the gravity core. Although the grain alignment deduced from AMS in core RC 22-15 does not show any clear pattern related to either contour-following or downslope currents, it is important to note that this core was recovered at a depth shallower than the region known to be influenced by the present deep boundary current (Richardson et al. 1981). Nevertheless, the palaeocurrent results remain enigmatic at this stage.

\section{Gravity core EN-078-GGC 1 (4815 m)}

Nine samples were analysed from this $83 \mathrm{~cm}$ long large-diameter gravity core. Three samples came from the Holocene, carbonate-enriched Unit 1; six additional samples were obtained from a 


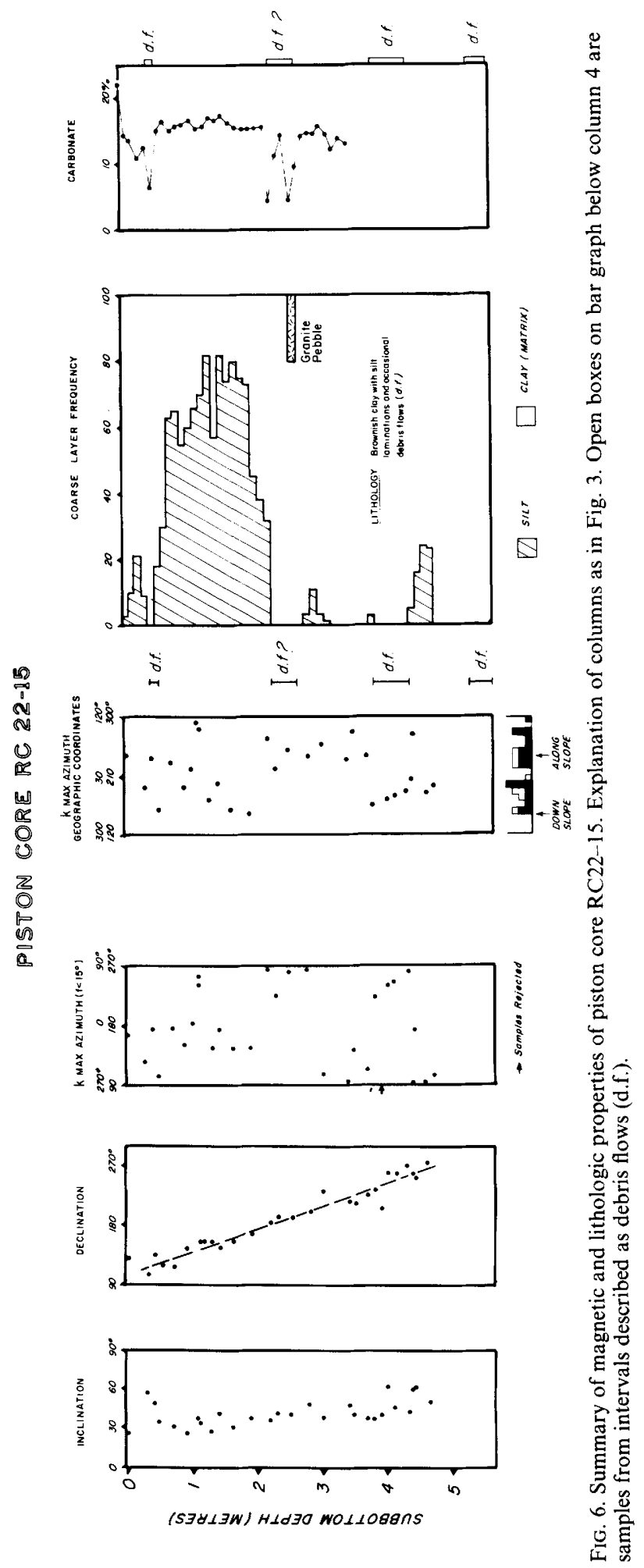


gravel-rich clay (Unit 3) below $22 \mathrm{~cm}$. Values of $f$ exceed 15 in one of three samples from Unit 1 and four of six samples from Unit 3. Because of the limited number of samples investigated in this core we have reported all values in Table 4 . However, the samples with foliation planes exceeding 15 should be interpreted cautiously. The gravity core was the only core in the present study which was sampled and analysed while still moist, which may cause some differences in sediment response to sampling and the AMS measurement procedure.

Both units 1 and 3 are strongly anisotropic, and show internally consistent directions of alignment which are significantly different from each other. Unit 1 shows an alignment direction which is consistent with contour-current flow, whereas Unit 3 shows alignment of the long axis approximately parallel to the channel trend (downslope flow).

\section{Discussion}

The initial results of AMS studies of three piston cores and one gravity core from the Nova Scotia continental rise indicate that the silt-laminated reddish-brown clay lithofacies may not be strictly associated with a single flow process in this environment. Further examination of cores across the bathymetric interval between cores RC 22-14 and RC 22-02 are necessary to determine whether a progressive change from downslope to alongslope orientations is preserved or whether some more complex relationship exists between these two sampling areas. Cores in this bathymetric interval are presently being analysed.
Based on our present results, the following inferences may be drawn about the processes of deposition over the depth interval of 4210-4925 $\mathrm{m}$ on the Nova Scotia rise:

(1) Our only Holocene samples, from the calcareous facies in the gravity core and in piston core $\mathrm{RC} 22-15$ indicate that this unit retains a fabric related to alongslope flow in spite of some degree of bioturbation. Although further study is warranted, we believe that this unit may be considered a 'contourite' based on its age, setting and magnetic fabric.

(2) The gravel-rich clay unit in the pre-Holocene section of the gravity core shows a strong downslope fabric alignment, and we consider this unit a type of fine-grained turbidite. Because it lacks primary sedimentary structures and contains significant gravel, we believe it deserves further sedimentological study to define the nature of the process(es) of deposition, and its regional distribution to determine whether deposition results from channelized flow.

(3) Samples from the homogeneous clay intervals in piston core RC $22-14$ clearly show a secondary disturbance of fabric which we believe results from bioturbation or possibly debris-flow deposition. If the latter is the transport agent, then we may infer that a change in magnetic remanence has taken place to statistically reorient magnetic minerals to the regional field following debris-flow deposition.

(4) The silt-laminated sequences in piston core RC 22-14 show a magnetic fabric alignment which is most consistent with downslope flow

TABLE 4. Gravity core EN-078-GGC $141^{\circ} 28.0^{\prime} \mathrm{N} ; 62^{\circ} 20.5^{\prime} \mathrm{W} ; 4815 \mathrm{~m}$

\begin{tabular}{cccccccccc}
\hline $\begin{array}{c}\text { Sample } \\
\text { depth (cm) }\end{array}$ & Inclination & Declination & $\begin{array}{c}\text { Mean } \\
\text { declinationt }\end{array}$ & $\begin{array}{c}\text { Azimuth } \\
\left(k_{\text {max }}\right)\end{array}$ & $\begin{array}{c}\text { Geographic } \\
\text { alignment }\end{array}$ & $f$ & $q$ & $h$ \\
\hline Unit 1 & & & & & & & & \\
8 & 49.2 & 207.1 & 221.0 & 098.8 & $237.7^{*}$ & 41.6 & .63 & $8.4^{\circ}$ \\
11.5 & 48.4 & 248.0 & 221.0 & 079.4 & 218.4 & 2.5 & .76 & 8.3 \\
14 & 58.5 & 253.1 & 221.0 & 105.0 & 244.0 & 14.6 & .99 & 6.6 \\
Unit 3 & & & & & & & & \\
23 & 45.6 & 231.8 & 221.0 & 019.8 & 158.8 & 12.3 & .18 & 34.4 \\
28 & 44.7 & 212.0 & 221.0 & 201.4 & 340.4 & 10.8 & .40 & 57.5 \\
38 & 49.2 & 222.1 & 221.0 & 177.6 & $316.6^{*}$ & 21.5 & .11 & 48.2 \\
48 & 45.1 & 200.0 & 221.0 & 219.1 & $358.1^{*}$ & 22.9 & .13 & 50.7 \\
58 & 37.3 & 196.3 & 221.0 & 181.5 & $340.5^{*}$ & 18.7 & .23 & 50.8 \\
68 & 48.0 & 219.0 & 221.0 & 059.9 & $198.9^{*}$ & 34.4 & .33 & 41.0 \\
\hline
\end{tabular}

* $\mathrm{f}>15$

$\dagger \sigma=20.0$

Inclination, declination following demagnetization to $23874 \mathrm{~A} / \mathrm{m}$. 
during deposition. However, four samples within Unit I of core RC 22-14 show alignments consistent with contour-current flow rather than turbidity currents.

(5) Silt-laminated sequences in core $\mathrm{RC} 22-02$, which comprise the entire $6 \mathrm{~m}$ long core, show a magnetic fabric alignment which is consistent with contour-current flow. Silt layers in core $\mathrm{RC} 22-02$ are generally thicker and less closely spaced than in core RC22-14, and the core is located beneath the present core of a strong thermohaline current, whereas $\mathrm{RC} 22-14$ is near the upslope margin of this flow.

(6) Samples from core RC22-15 do not show a clearly defined preferential alignment related to either downslope or alongslope flow conditions. At the present time, the strongest alongslope currents are restricted to depths greater than this core. While it is possible that some complex interaction of downslope and alongslope processes results in a 'smearing' of the directional information preserved in AMS, we prefer to leave interpretation of these data until such time as unambiguous results relating lithofacies and depositional processes in other settings provide a less subjective basis for discussing complexities.

(7) Highest percent anisotropy values are observed in Unit III of the gravity core (downslope alignment) and in piston core RC22-15 (no clear preferential alignment) rather than in core RC22-02 which shows the strongest alongslope alignment. Anisotropy values are low in Unit 2 of core RC22-14 which shows signs of post depositional deformation.

\section{Conclusions}

We believe that the anisotropy of magnetic susceptibility technique (AMS) holds considerable promise in differentiating downslope and alongslope depositional processes of fine-grained sediments on the Nova Scotia continental rise. Our present results from four cores in general support the hypothesis of Hollister (1967) that contour-following bottom currents have played a role in sediment redistribution on the continental rise during the glacial stages of the Pleistocene. Alongslope currents are also important depositional agents in the Holocene. However, our preliminary results demonstrate that downslope magnetic fabric alignments occur as frequently as alongslope alignments.

ACKNOWLEDGMENTS: Support for AMS studies was provided by the US National Science Foundation (OCE80-12897); cores were collected through support from US Office of Naval Research (T0210-82-11111). Archive facilities at L-DGO are supported by NSF through OCE81-22083. We are grateful to both agencies for their support of this work. N. Iturrino assisted in collection of gravity cores, B. Tucholke collected piston cores. J. Kostecki and F. Hall carried out AMS and remanence measurements. J. Broda loaned the gravity corer. V. Kolla was instrumental in obtaining support for this project. E. Free and C. Elevitch typed the manuscript. This paper was reviewed by $C$. Hollister, N. McCave, J. Damuth, W. Ruddiman, D.A.V. Stow, A. Bouma and A.I. Rees. L-DGO Contribution \#3621.

\section{References}

Auffret, G.-A., Sichler, B. \& Coleno, B. 1981. Deep-sea texture and magnetic fabric indicators of bottom currents regime. Oceanologica Acta, 4, 475-88

Bulfinch, D.L., Ledbetter, M.L., Ellwood, B.B. \& BALSAM, W.L. 1982. The high-velocity core of the Western Boundary Undercurrent at the base of the U.S. continental rise. Science, 215, 970-3.

Crimes, T.P. \& Oldershaw, M.A. 1967. Palaeocurrent determinations by magnetic fabric measurements on the Cambrian rocks of St. Tudwal's Peninsula, North Wales. Geol. J., 5, 217-32.

ELLwOOD, B.B. 1980. Application of the anisotropy of magnetic susceptibility method as an indicator of bottom-water flow direction. Marine Geol., 34, M83-90.

_- \& LedBetTER, M.T. 1979. Palaeocurrent indicators in deep-sea sediment. Science, 203, 1335-7.
Granar, L. 1958. Magnetic measurements of Swedish varved sediments. Arkiv Geofysik, 3, 1-40.

Hamilton, N. \& ReEs, A.I. 1970. The use of magnetic fabric in paleocurrent estimations. In: Runcorn, S.K. (ed.), Paleogeophysics. Academic Press, New York. 445-64.

HollisTER, C.D. 1967. Sediment Distribution and Deep Circulation in the Western North Atlantic. Unpubl. doctoral dissertation, Columbia University in the City of New York, USA.

_ \& HEEZEN. B.C. 1972. Geologic effects of ocean bottom currents: Western North Atlantic. In: Gordon, A. (ed.), Studies of Physical Oceanography 2. Gordon \& Breach, London. 37-66.

Horn, D.R., Ewing, M., Horn, B.M. \& Delach, M.N 1971. Turbidites of the Hatteras and Sohm Abyssal Plains, Western North Atlantic. Marine Geol., 11, 287-323. 
KENT, D.V. 1973. Post-depositional remanent magnetization in a deep-sea sediment. Nature, Lond., 246, $32-4$.

_- \& LowrIE, W. 1975. On the magnetic susceptibility of deep-sea sediment. Bull. geol. Soc. Am., 87, 321-39.

KING, R.F. \& ReES, A.I. 1962. The measurement of the anisotropy of magnetic susceptibility of rocks by the torque method. J. geophys. Res., 67, 1565-72.

LEDBETTER, M.T. 1979. Fluctuations of Antarctic Bottom Water velocity in the Vema Channel during the last 160,000 years. Marine Geol., 33, 71-89.

— \& Ellwood, B.B. 1980. Spatial and temporal changes in bottom-water velocity and direction from analysis of particle size and alignment in deep-sea sediment. Marine Geol., 38, 245-61.

REes, A.I. 1961. The effect of water currents on the magnetic remanence and anisotropy of susceptibility of some sediments. Geophys. J.R. astron. Soc., $\mathbf{5}$, 235-51.

REES, A.I. 1965. The use of anisotropy of magnetic susceptibility in the estimation of sedimentary fabric. Sedimentology, 4, 257-71.

- Brown, C.M., Hailwood, E.A. \& Riddy, P.J., 1982. Magnetic fabric of bioturbated sediments from the northern Rockall Trough: Comparison with modern currents. Marine Geol., 46, 161-73. \& Frederick, D. 1974. The magnetic fabric of samples from the Deep Sea Drilling Project, Legs I-VI. J. sed. Petrol. 44, 655-62.

VON RAD, U. \& ShePard, F.P. 1968. Magnetic fabric of sediments from the La Jolla Submarine
Canyon and fan, California. Marine Geol., 6, 145-79.

REES, A.I. \& WoDAlL, W.A. 1975. The magnetic fabric of some laboratory deposited sediments. Earth planet. Sci. Lett., 25, 121-30.

Richardion, M.J., Wimbush, M. \& Mayer, L. 1981. Exceptionally strong near-bottom flows on the continental rise off Nova Scotia. Science, 213, 887-8.

SPIESS, F.N. \& MUdiE, J. 1970. Small-scale topographic and magnetic features. In: Maxwell, A.E. (ed.), The Sea 4. John Wiley, New York. 205-50.

Stanley, D.J., Swift, D.J., Silverberg, N., James, N.P. \& SutToN, R.G. 1972. Late Quaternary progradation and sand spillover on the outer continental margin off Nova Scotia, southeast Canada. Smiths. Contr. Earth Sci. 8. Smithsonian Inst. Press, Washington, D.C. 88 pp.

STow, D.A.V. 1979. Distinguishing between finegrained turbidites and contourites on the Nova Scotia deep water margin. Sedimentology, 26, 371-87.

- \& Bowen, A.J. 1980. A physical model for the transport and sorting of fine-grained sediment by turbidity currents. Sedimentology, 27, 31-46.

\& LOVELl, J.P.B. 1979. Contourites: their recognition in modern and ancient sediments. Earth Sci. Rer. 14, 251-91.

TUCHOLKE, B.E. 1982. Origin of longitudinal triangular ripples on the Nova Scotia continental rise. Nature, Lond., 296, 735-7.

A.N. SHOR, D.V. KENT, R.D. Flood, Lamont-Doherty Geological Observatory of Columbia University in the City of New York, Palisades, New York 10964, USA. 